\title{
Do Dois ao Múltiplo na terra do Um: a expenência antropológica de David Maybury-Lewis
}

\author{
Renato Sztutman \\ D outorando em A ntropologia Social - USP
}

RESUMO : Este artigo busca uma compreensão da trajetória do antropólogo britânico, radicado nos EUA, D avid Maybury-Lewis. Aborda aspectos de sua formação intelectual, que envolveram uma longa pesquisa entre os $\mathrm{X}$ avante e um estudo comparativo sobre os povos de línguajêe bororo do Brasil Central. Maybury-Lewis é um nome central para o desenvolvimento de um "americanismo tropical". Entre suas contribuições etnográficas e teóricas, podese citar a elaboração de um modelo analítico jê e bororo, a renovação dos estudos de parentesco e a reflexão sobre a relação entre povos indígenas e o Estado. Um tema parece, com efeito, permear a sua obra: 0 das organizações dualistas. Não por menos, esse foi o motivo de um longo debate com a obra de LéviStrauss, que será aqui destacado.

PALAVRAS-CHAVE: etnologia indígena, povos de língua jê e bororo, dualismo, multiculturalismo, Estado.

Ora, a experiênciaé, em antropologia, a nossa inserção de sujeitos sociais num todo social em quejá está efetuada a síntese que a nossa inteligência procura laboriosamente, porquanto vivemos na unidade de uma única vida todos os sistemas que compõem a nossa cultura. Pode-se tirar algum conhecimento dessa síntese que somos. Mais: 0 aparelho do nosso ser pode ser desfeito e refeito pela viagem, assim como podemos aprender a falar outras línguas.

(Merleau-Ponty) 
A antropologia de David Maybury-Lewis revela uma notável ressonância entre problemas sugeridos pela teoria e aqueles colhidos nos vários níveis da experiência - das primeiras impressões na infância, quando vivia em uma colônia britânica, ao trabalho de campo entre duas sociedades dualistas do Brasil Central e ao ativismo político que redundou na fundação de uma organização não governamental dedicada à luta pelos direitos dos povos indígenas de todo o mundo. A trajetória do professor de Harvard, inglês radicado nos EUA, sugere que o ofício antropológico se vê não raro associado a uma vocação, no sentido que Max Weber atribui ao termo - um ofício que deve ser percorrido com paixão e que suscita um estado singular de embriaguez para que, então, se encontre e obedeça ao "demônio que tece as teias de sua vida" (1967: 52; grifo do autor).

Esse demônio, no caso de Maybury-Lewis antropólogo, já se manifestara na infância por uma curiosidade tamanha pelas formas da diversidade. É com um sabor por assim dizer felliniano que ele narra, no depoimento transcrito a seguir, os primeiros encontros furtivos com os cameleiros em Hyderabad, em uma região que hoje pertence ao Paquistão e que se via subjugada por um Estado ocidental. David, nascido em 1929 nessa mesma cidade, era filho de um oficial britânico e se via apartado do mundo nativo que o circundava, ora pela proteção que recebia da família e dos serviçais, ora pela incompreensão das línguas dos diferentes povos que ali habitavam. Essa atmosfera de separação e incomunicabilidade não fazia senão crescer o desejo de conhecer um mundo outro, desejo que permaneceria recalcado até a conclusão do curso de graduação, quando dos primeiros contatos com os estudos de Etnologia. O pluralismo e a multiplicidade que povoaram as primeiras experiências de $\mathrm{D}$ avid, que partiria aos sete anos para a Inglaterra com sua família, aos poucos se tornava uma questão decisiva, digna de orientar escolhas e inspirar reflexões. Não por acaso, depois de servir, entre 1947 e 1949, ao exército britânico, decidiu dedicar-se ao estudo de línguas na Universidade de Cambridge, confirmando sua avidez pela comunicação com outros povos e em outros ter- 
mos e, com efeito, em 1952, já podia considerar-se um poliglota, pois dominava com destreza cinco idiomas distintos, sendo capaz de passar de um a outro com grande aptidão.

A descoberta da Etnologia ocorreu em 1952 por ocasião de uma reunião de americanistas ocorrida em Cambridge. Entusiasmado com as discussões que presenciara, D avid apresentou-se ao professor Herbert Baldus, alemão que ensinava e realizava pesquisas no Brasil, manifestando o seu enorme interesse em conhecer os povos indígenas da América do Sul. Baldus encorajou-0, mas sem saber que, de maneira decidida e muito rápida, D avid e sua esposa Pia estariam a bater a porta de sua casa em São Paulo. Ao deixar a Inglaterra em 1953, D avid realizava um desejo infantil ao mesmo tempo em que concebia um projeto profissional que iria acompanhá-lo por toda a sua vida. Ele sabia que, daí em diante, teria de se dedicar intensamente aos estudos americanistas e, enfim, escolher um grupo entre 0 qual teria de viver e, assim, tornar-se um verdadeiro antropólogo.

As pesquisas de Maybury-Lewis no Brasil iriam inaugurar uma nova fase do americanismo. 0 ímpeto inicial que o conduzia a estudar etnologia indígena na Escola Livre de Sociologia e Política culminaria em um esforço de consolidação dessa área de conhecimento, sobretudo por selar um diálogo, anos mais tarde, com as principais linhas analíticas da Antropologia britânica e anglo-saxã em geral. A vinda do jovem pesquisador ao Brasil significava tanto a abertura de um campo de investigação pouco explorado pelo americanismo da época - as sociedades indígenas do Brasil Central, de língua jê e bororo, que o fascinaram desde 0 início devido aos seus intrigantes esquemas duais- como o confronto dos dados etnográficos obtidos com a produção antropológica contemporânea, debruçada prioritariamente sobre os estudos de parentesco.

Enquanto tomava conhecimento da literatura disponível sobre os povos sul-americanos, Maybury-Lewis se interessou sobremaneira pelos Xavante, contatados na década de 1930 porém fortemente avessos às relações com os agentes da sociedade brasileira, o que lhes conferia, na mídia, uma reputação de belicosidade. A imagem de uma popula- 
ção que se recusava a estabelecer comunicação com o mundo dos brancos e para quem a língua portuguesa permanecia ausente de inteligibilidade fascinava o jovem pesquisador. Não obstante, os obstáculos para a pesquisa com um grupo por assim dizer arredio eram inúmeros, o que exigia que fossem definidas certas estratégias. Conhecer os Xavante, vencer as barreiras da incomunicabilidade impostas desde a infância, se tornava, assim, um projeto audacioso que deveria ser perseguido a todo custo, nem que para tanto fosse necessário despender esforços e esperas. Não por menos, a decisão tomada por Maybury-Lewis foi a de adiar a visita a esse grupo para um momento posterior. Enquanto não se via devidamente preparado, realizaria uma visita a um grupo indígena vizinho, os Xerente, que contavam com mais de um século de convívio com brasileiros - logo, dominavam o português - e falavam uma língua muito próxima ao xavante. A temporada entre os Xerente serviria, assim, de trampolim para a pesquisa verdadeiramente desejada.

D epois de transitar por entre cursos e bibliotecas da Escola Livre de Sociologia e Política, Maybury-Lewis partia aos X erente para uma estadia de oito meses. Era a sua primeira experiência de campo, o que lhe renderia a redação da dissertação de mestrado. Já a visita aos Xavante, da qual resultaria o seu doutoramento, ocorreria apenas anos mais tarde. Para tanto, Maybury-Lewis retornava à Inglaterra, inscrevendo-se na Universidade de O xford, onde se preparava para a nova inserção no campo - lá iria aprender com grandes mestres da Antropologia Social e tomar conhecimento dos imensos debates sobre o parentesco. Somente após passar por esse ritual acadêmico, ele pôde voltar, em 1958, para o Brasil, junto à sua esposa e a seu filho de apenas um ano, para realizar uma estadia de cerca de um ano entre os indígenas. Vale notar que ambas as experiências de pesquisa, entre os X erente e os $\mathrm{X}$ avante, assim como o período compreendido entre uma e outra, foram descritas de maneira instigante em 0 selvagem e 0 inoœnte (1990 [1965]), livro que alia a minúcia etnográfica ao tom biográfico, desvelando aspectos subjetivos da constituição da obra do autor. 
Revista de Antro pologia, São Paulo, USP, 2002, v. 45 no 2.

$* * *$

No momento de sua chegada ao Brasil, a produção etnográfica sobre a América do Sul era pouco satisfatória ou mesmo incipiente se comparada, por exemplo, aos estudos africanistas. 0 mesmo pode ser afirmado com respeito ao rendimento teórico que essa produção apresentava. Como alega Anne-Christine Taylor (1998 [1984]), a propósito do americanismo que se desenvolveu até essa época, tratava-se de um "monografismo estrito, um anti ou a-historicismo irredutível [que espe-lhava] a dificuldade manifesta em se libertar de uma alternativa fixa entre um determinismo ecológico sumário e um idealismo mais ou menos temperado" (: 5). No Brasil do período, a cena americanista era povoada pelos trabalhos de Curt Unkel Nimuendaju, nos anos 1930 e 1940, e, posteriormente, pelos de Herbert Baldus e Egon Schaden. Nimuendaju, pesquisador alemão, foi certamente o desbravador da Etnologia sulamericana. Funcionário do Museu Paulista e do Serviço de Proteção ao Índio, dedicou sua vida para a pesquisa entre diferentes grupos indígenas - estima-se que ele tenha visitado cerca de meia centena deles $^{1}$. D entre as suas monografias mais importantes, três delas, dedicadas a grupos centro-brasileiros de língua jề ${ }^{2}$, foram traduzidas ao inglês por Robert Lowie, antropólogo norte-americano com quem mantinha uma relação estreita de colaboração.

Os trabalhos de Nimuendaju constituem, por assim dizer, uma "E tnologia heróica", qual seja, um esforço menos de sistematização e teorização que de coleta e acúmulo de dados etnográficos sobre povos indígenas de diferentes regiões do Brasil, o que preenchia a enorme lacuna existente. As conseqüências dos dados do pesquisador para a teoria antropológica eram muitas vezes analisadas por Lowie, o que implicava a inclusão do americanismo nos debates correntes da época. Não obstante, resultavam dessa primeira etnografia interpretações que, ao justapor os modelos analíticos disponíveis à empiria, deparavam-se com anomalias, ou seja, realidades que contradiziam princípios gerais 
inferidos pela disciplina ${ }^{3}$. 0 novo investimento na pesquisa de campo no Brasil Central aliada à depuração das questões antropológicas em voga possibilitaria, dessa feita, a D avid Maybury-Lewis desfazer alguns desses mal-entendidos conceituais.

O utro pioneiro do americanismo no Brasil foi Claude Lévi-Strauss, autor com o qual a obra de Maybury-Lewis não pouparia discussões. Em 1935, Lévi-Strauss chegava ao Brasil para ensinar Sociologia e Antropologia na recém-fundada Universidade de São Paulo, e logo se envolvia em atividades de pesquisa, tais quais a primeira e breve visita aos Bororo, em 1936, e a longa expedição pelo Brasil Central e Oriental, em 1938. D epois dessas experiências, integrando a Société des Américanistes, passava a publicar uma série de artigos e verbetes sobre povos sul-americanos, além de uma monografia sobre os Nambikwara (Lévi-Strauss, 1948) ${ }^{4}$. Não obstante, ele jamais voltaria a realizar pesquisas de campo, dedicando-se a trabalhos de cunho comparativo, contribuições inestimáveis para a teoria antropológica da segunda metade do século XX.

Herbert Baldus e Egon Schaden foram os primeiros etnólogos de formação em São Paulo, ocupando cadeiras, respectivamente na Escola Livre de Sociologia e Política e na Universidade de São Paulo. Ambos concederam privilégio à empiria e tornaram compatíveis perspectivas de diferentes escolas, como o difusionismo, o culturalismo e o funcionalismo. Criavam uma "Etnologia primeira" que se destacava pelo esforço de sistematização de dados provenientes das etnografias mais díspares. Embora incentivassem a realização de pesquisas etnográficas, preferiram transitar por entre diversos grupos a ter de se ater a um único por um tempo muito longo, o que significou a produção menos de monografias de grande profundidade que de balanços e reflexões gerais sobre temas relevantes para o estudo de povos indígenas sul-americanos. Nota-se, também, que ambos os autores faziam conviver uma abordagem que conferia ênfase ao problema da aculturação com outra que se mantinha mais próxima dos temas da E tnologia clás- 
Revista de Antropologia, São Paulo, USP, 2002, v. 45 no 2.

sica, como mitologia, ritual e xamanismo ${ }^{5}$. A conciliação entre essas perspectivas aparecia, tanto para Baldus como Schaden, como ponte para pensar um envolvimento com a política indigenista brasileira, na época representada pelo Serviço de Proteção ao Índio. Essa preocupação da Etnologia com aspectos políticos surtiria uma certa inflexão na trajetória de Maybury-Lewis, como buscarei ressaltar mais adiante. Não obstante, a ausência de uma escola consolidada a que faz referência 0 próprio Schaden ${ }^{6}$ iria de encontro com os caminhos do futuro acadêmico de Harvard, para quem, é necessário fazer a Etnologia regional refletir debates teóricos fundamentais, o que pressupõe que esta não pode prescindir do manejo de lentes específicas.

No quadro da Antropologia norte-americana, a corrente teórica que serviria de contraponto para Maybury-Lewis é a ecologia cultural, abraçada, entre outros, por Julien Steward. E ditor do $\mathrm{H}$ andbook of Southamerican Indians (1945), Steward buscava, na esteira do neo-evolucionismo de Leslie White e dos estudos difusionistas caros à sua época, a reabilitação de esquemas de interpretação materialistas para apreender os diferentes níveis de integração com o meio ambiente a que se vêem subsumidos os povos americanos. Steward reunia, assim, pesquisas centradas na base material desses povos, partindo de uma perspectiva inicialmente economicista e, em seguida, ecologista, debruçada, contudo, sobre uma noção de economia definida, grosseiramente, como conjunto de técnicas e subsistência. Como pontua Taylor (1998 [1984]), sobre a ecologia cultural e o contexto da produção americanista que precede à década de 1970, trata-se de uma

Etnologia que sempre prescindiu de reflexão sociológica, tradicionalmente pouco habituada a manipular simultaneamente níveis distintos de realidade e analisar articulações/ contradições, em que o determinismo geográfico servia, há muito, como princípio explicativo. (: 19)

Tudo isso fazia, ainda segundo a autora, do americanismo tropical "a mais a-sociológica das etnologias regionais" (: 20). 
A principal razão que levaria Maybury-Lewis a escrever contra a escola de Steward responde a uma injustiça que envolve uma concepção empobrecida de cultura, qual seja, o reconhecimento dos povos indígenas do Brasil Central como "marginais" diante do quadro sul-americano geral, sobretudo os Andes, uma vez vislumbrado o baixo desenvolvimento de sua cultura material e tecnologia. $\mathrm{O}$ fato de a economia desses povos basear-se predominantemente na caça e na coleta era, desse modo, interpretado como resultado das baixas condições oferecidas pelos ecossistemas dos cerrados e implicava a configuração de sociedades em nível muito reduzido de civilização, a bem dizer, sociedades "primitivas" por excelência. Não obstante, etnografias um tanto mais atentas às sociedades do Brasil Central, como as de Nimuendaju e as do próprio Lévi-Strauss, já questionavam essa idéia vaga de marginalidade tendo em vista a complexidade dos sistemas sociais ali operantes. Antes de Maybury-Lewis, Lévi-Strauss, em "A noção de arcaísmo em Antropologia" (1976b [1952]), interrogava-se pelo fato de como sociedades de tão baixa diferenciação tecnológica poderiam ter desenvolvido uma sociologia e uma cosmologia tão sofisticadas. O ra, para o jovem Lévi-Strauss, o desafio residia em passar da interpretação negativista oferecida pelos estudos de cultura material para uma abordagem propriamente sociológica. De modo análogo, para MayburyLewis, a positividade desses povos deveria ser buscada no seio de seus sistemas sociais, organizados por uma profusão de pares de metades, ainda que para decifrá-los cumprisse enfrentar muitas aventuras conceituais.

Maybury-Lewis deveria contrapor-se tanto às concepções dominantes da ecologia cultural que, ao negligenciar aspectos fundamentais de sua configuração sociológica, reduziam os povos do Brasil Central a uma condição de marginalidade, como ao hermetismo analítico que reinava na Etnologia paulista e, assim, dificultava a realização de um trabalho dotado de rigor propriamente científico. D e um lado, um arsenal conceitual ofuscava o "ser" das sociedades em questão, relegando-as à coerção do meio ambiente hostil; de outro, a ausência de um quadro 
Revista de Antro pologia, São Paulo, USP, 2002, v. 45 no 2.

metodológico estabelecido freava a investigação mais aprofundada. Cumpria, desse modo, trazer a tradição do empirismo britânico para 0 americanismo que se configurava lentamente no Brasil, nos EUA e em outras partes do mundo, o que exigia um maior foco no trabalho de campo demorado e a integração da produção etnográfica a um debate teórico e metodológico particular?.

Como já salientado, quando Maybury-Lewis partiu com sua família para viver entre os Xavante, o parentesco figurava como o grande tema da Antropologia social, visto que se acreditava ser possível inferir por esse domínio a imagem da estrutura social como um todo ${ }^{8}$. Essa equação revelava, ademais, uma concepção particular da "sociedade primitiva" como "baseada no parentesco". Um dos pontos da crítica etnográfica de Maybury-Lewis consistiria, com efeito, em questionar essa idéia, ora para problematizar o conceito de "primitivo", ora para dissolver a primazia dos estudos de genealogia diante de outros aspectos como teorias nativas de concepção, transmissão de nomes, entre outros. Ressalte-se que Maybury-Lewis teve Rodney Needham como orientador, o que o distanciou, de certa forma, da discussão sobre a teoria da descendência, aplicada por Radcliffe-Brown e Evans-Pritchard em seus estudos sobre sociedades africanas, e 0 aproximou de certo modo da teoria da aliança e do método estrutural de Lévi-Strauss, ainda que fosse para lançar críticas quando da interpretação de seus dados sobre os Jê. Em Structure and sentiment (1962), Needham, também um dos tradutores de A s estruturas elementares do parentesco para a língua inglesa, teceu diversas considerações críticas ao estruturalismo ao buscar introduzir na teoria geral do parentesco a noção de interesse, recuperando em seus modelos analíticos um lugar para o agente, que teria sido abandonado por aquela Antropologia sem sujeitos. As indagações de Needham, à sua parte, colocavam em risco distinções fortemente estabelecidas por Lévi-Strauss entre modelo empírico, modelo indígena e modelo estatístico.

Em 1960, Maybury-Lewis defendia sua tese de doutorado, sendo examinado por E. E. Evans-Pritchard e Edmund Leach. Em 1967, pu- 
blicou-a sob o título A sociedade xavante (1984 [1967]), iniciando uma investigação comparativa sobre as sociedades indígenas do Brasil Central, algo que já estava sendo levado adiante com a formação de um grupo de pesquisa na Universidade de Harvard, onde passava a ensinar em 1960. A sociedade x avante ${ }^{9}$ representa, nesse cenário, uma contribuição fundamental para a constituição da Etnologia indígena contemporânea, sempre preocupada com temas clássicos, como parentesco, cosmologia e mitologia. Ao lado de Marriage among the Trio, sobre a Guiana, publicado por Peter Rivière em 1969, traz as Terras Baixas da América do Sul para os debates calorosos da Antropologia de tradição britânica, inaugurando um novo período de reflexão. O ra, se a Etnologia regional se constitui pela sua entrada em um campo de debate teórico, também esse debate acabou por ser incrementado pelos dados advindos da nova etnografia. 0 que fazer, por exemplo, quando os dados que saltam à observação não correspondem às teorias disponíveis? MayburyLewis evidenciou, nesse sentido, a insuficiência tanto da teoria da descendência como da teoria da aliança para compreender 0 caso xavante e, de maneira mais ampla, jê e bororo, uma vez que entre esses grupos não era possível vislumbrar a formação de grupos de descendência tampouco a operação de regras prescritivas de casamento, mesmo quando um ou outro se manifestavam (os Xavante, por exemplo, apresentam grupos de descendência patrilineares) isso não se dava de modo totalizante, como se vislumbrava em outras paisagens etnográficas, porém de modo subsidiário, o que sugeria, ali, que o parentesco não era capaz de oferecer um modelo total para a vida social.

A monografia de Maybury-Lewis ofereceu-se, ademais, como contribuição à teoria do parentesco humano, não apenas pelo fato de o parentesco não totalizar o conjunto das relações sociais observadas, o que põe em risco a visão de Radcliffe-Brown da sociedade primitiva, mas também pela idéia de que, para apreendê-lo como sistema, é preciso que ele deixe de ser definido por critérios meramente biológicos ou genealógicos. Em outras palavras, Maybury-Lewis acredita que o estudo 
do parentesco não pode ser dissociado da compreensão das relações sociais concebidas por meio de categorias nativas de entendimento. 0 autor extrai, dessa feita, as conseqüências de uma concepção categorista do parentesco, qual seja, esse deve ser referido prioritariamente como idioma que permeia as relações sociais. A lição da etnografia jê então empreendida diz respeito ao fato de as categorias de parentesco não se referirem a uma rede de relações biológicas, mas conformarem um sistema de classificação que deriva de uma teoria social e do lugar do indivíduo nessa teoria. Tais idéias, desenvolvidas em A sociedade x avante, seriam aprofundadas e testadas em uma visada comparativa reunindo a etnografia dos vários grupos de língua jê e bororo do Brasil Central - 0 Projeto Harvard Brasil Central, que redundou na publicação da coletânea D ialectical societies: the $\mathrm{G}$ ê and Bororo of $\mathrm{C}$ entral Brazil, em 1979. O projeto reuniu, entre a década de 1960 e 1970, pesquisadores de perfis e posturas teóricas algo diversos da Universidade de Harvard e do Museu Nacional (UFRJ) para discutir problemas relacionados à estrutura social dos grupos jê e bororo ${ }^{10}$. No campo, cada qual se deparou com uma grande variabilidade sociológica: os Bororo apresentavam descendência matrilinear, os Xavante e os X erente, patrilinear, outros, como os Kayapó revelavam princípios de descendência pouco (ou nada) operantes. Entre os Timbira, a uxorilocalidade, baseada no agrupamento de famílias extensas ou casas em torno de linhas femininas inter-relacionadas, promovia a ilusão de uma matrilinearidade que de fato não poderia ser comprovada.

A proposta de Maybury-Lewis, que coordenava o projeto, consistia na busca de novos instrumentos de análise à medida que grupos corporados e regras prescritivas de aliança e descendência não se verificavam nos termos vislumbrados por outras etnologias, debruçadas sobre a África e a 0 ceania. As receitas para a pesquisa de campo, que já pressupunham teorias, deveriam ser refeitas e, para tanto, o autor e seus colegas e alunos deveriam empreender o que Viveiros de Castro (1993) denominou de "dissolução culturalista", ou seja, uma maior ênfase no estudo das categorias nativas de entendimento, priorizando aspectos 
Renato Sztutman. Do Dois ao Múltiplo na Terra do Um

ideológicos, no sentido que Clifford Geertz (1978 [1973]) e Louis D umont (1995 [1966]) atribuem ao termo (jamais como mascaramento da realidade). Três poderiam ser referidos como os pontos principais dessa nova empresa: 1) o mergulho em categorias nativas como via de acesso a instituições em vez de importar conceitos advindos de realidades etnográficas outras; 2) produzir, a partir das etnografias individuais, uma "comparação controlada", sem grandes vôos teóricos, apenas para cercar as recorrências culturais; 3 ) trabalhar com teorias nativas e modelos conscientes de maneira a recuperar o lugar dos agentes que se vêem diante dos dilemas colocados pela estrutura sociall1.

O grupo de Harvard não era, entretanto, unânime, como pode ser notado em uma divergência entre posturas no interior de D ialectical societies ${ }^{12}$. Ao lado da inflexão culturalista compartilhada por autores como o próprio Maybury-Lewis, Júlio César Melatti e Roberto Da Matta, Terence Turner, que estudou os Kayapó G orotire, aproximava-se de uma tradição marxista que privilegiava a reflexão sobre uma base de produção em detrimento dos aspectos puramente ideológicos dos sistemas sociais. A contribuição de Turner consiste em encompassar 0 dualismo kayapó - e de modo geral, jê e bororo - à relação de dominação estabelecida no interior das casas (households) entre um sogro e um genro, uma vez atestado um padrão uxorilocal de residência. Tal tese contrapõe-se à de Maybury-Lewis, para quem o dualismo, representado pela profusão de metades cerimoniais e bélicas (e não matrimoniais como se verificava na Austrália), é a expressão de princípios ideológicos fundamentais que prezam pela simetria e harmonia. Turner (1979 e 1984) recusa esse ideal de complementaridade, alegando que os sistemas jê e bororo só podem ser compreendidos se revelado o princípio hierárquico a eles inerentes e que se reproduz desde o nível doméstico - a casa - até os níveis políticos e cerimoniais. Ora, o debate em torno do aspecto da simetria desse intrigante dualismo invade outros planos, desta vez menos ligados à infra-estrutura material, como o revelado quando do embate com os escritos de Lévi-Strauss. 
Revista de Antro pologia, São Paulo, USP, 2002, v. 45 no 2.

A discussão sobre o lugar do dualismo no Brasil Central - um sistema ideológico baseado em uma fórmula antitética que ordena os diversos aspectos da vida social - povoa o conjunto da obra de Maybury-Lewis, figurando desde a publicação de um artigo em reação às teorias de LéviStrauss, "The analysis of dual organizations: a methodological critique" (1960), até a coletânea recente, editada com Uri Almagor, The attraction of opposites: thought and society in dualistic mode (1989). Em A sociedade x avante, 0 autor apontava a dicotomia fundante entre as categorias "nós" e "eles" (waniwimhã e watsire'wa) como modelo capaz de melhor explicar a vida social - e, se não explica tudo (o intenso facciosismo que assola as comunidades deve ser, por exemplo, tomado como independente dos diversos sistemas de metade), ao menos serve de referência indispensável para que os agentes orientem a sua experiência. A noção de "sociedades dialéticas", empregada para designar as sociedades jê e bororo, aponta a posição central dessa teoria social que postula que a harmonia vislumbrada como causa final só pode ser alcançada pela complementaridade dos contrários ${ }^{13}$.

Perdura no tempo a insistência no tema, como se pode notar na releitura presente em The attraction of opposites, desta vez abrangendo um recorte etnográfico mais amplo, não restrito ao Brasil Central, mas que também inclui sítios esparramados por todo o globo, como a Austrália, os Andes e a Melanésia. Na introdução ao livro, "The quest for harmony", o autor amplia a definição do dualismo como pensamento social baseado na possibilidade de atingir a harmonia por meio de um esquema de coisas gerado pela interação de dois princípios antitéticos e complementares, no qual os sistemas de metade não seriam mais que uma das possíveis expressões institucionais. Com efeito, o autor se distancia cada vez mais de uma concepção sociologista do problema para apreendêlo como ideologia ou teoria social que não necessariamente se atualiza em todos os domínios da vida social. 0 problema morfológico que baseou os primeiros anos da 
pesquisa no Brasil Central acaba por ser definitivamente diluído por um problema filosófico mais amplo e que, justamente por isso, pode ser avistado em outras paisagens etnográficas.

As asserções contidas em The attraction of opposites suscitaram reações de Lévi-Strauss em um de seus livros mais recentes, $\mathrm{H}$ istória de lince (1993b [1991]), reavivando um debate antigo em torno do sentido e alcance do problema do dualismo ameríndio. Não surpreende que este tema constitui um dos eixos centrais das obras de ambos os antropólogos, que partiram de intuições para então desenvolver análises conceituais reveladoras. 0 debate em torno do dualismo, tomado a princípio como problema de organização social para, em seguida, ser vislumbrado como o motor de um pensamento, abriga um movimento duplo de distanciamento e aproximação entre os dois autores. Há, nos primeiros textos das décadas de 1950 e 1960, um consenso inicial entre ambos no que diz respeito à definição do dualismo menos como instituição ou expressão de uma regra positiva de casamento do que como "mentalidade" (Carneiro da Cunha, 1993). Em outras palavras, acreditam que, para compreender o fenômeno no Brasil Central, é preciso ir além do domínio do parentesco, visto que, em uma primeira instância, os sistemas de metade ali observados não podem constituir classes matrimoniais como se verificou na Austrália. A mbos procuram, assim, restituir positividade aos sistemas sociais jê e bororo, tentando compreendê-los não pelo que neles se ausenta, mas pelo sentido que subjaz à profusão dos pares de metades e à recorrência a concepções duais sobre 0 cosmos.

As discordâncias logo começam a pulular se considerados os pressupostos teóricos e metodológicos que cada autor guarda em mente, bem como as suas visadas etnológicas sobre o problema. Algo que separa os autores é certamente a difícil arte de transformar a experiência empírica em modelo analítico. Se Lévi-Strauss aventura-se na busca de realidades mais subterrâneas e, portanto, menos evidentes ao discurso nativo, Maybury-Lewis permanece propositalmente no plano da teoria social 
local, tentando se aproximar de um conjunto de concepções evidentes o suficiente para informar a ação e atribuir sentido à experiência. Se ambos concordam que o dualismo não pode ser outra coisa que um modelo, o que os distingue é a noção de modelo em jogo. Para MayburyLewis, esta seria como um ponto de referência básico que torna compreensível um certo número de idéias, regras e ações, além de fornecer uma teoria social e "o porquê da organização, tal qual feita pelos Xavante, de suas categorias cosmológicas e sociais; o porquê do modo pelo qual se dão os alinhamentos faccionários e que considerações os próprios Xavante tecem ao planejar suas estratégias de ação social" (1984 [1967]: 6).

Segundo Maybury-Lewis, mesmo a lógica do facciosismo, que engendra, independentemente das organizações duais, agrupamentos políticos temporários, não perde a referência em categorias de entendimento geradas pelo esquematismo dualista.

Se para Maybury-Lewis de A sociedade xavante (1984 [1967]) e D ialectical societies (1979), o dualismo jê e bororo consiste na busca da harmonia entre os contrários, para Lévi-Strauss, em um texto como "As organizações dualistas existem?" (1976 [1956]), este nada mais é que uma "cortina de fumaça", que encobre uma realidade outra, desta vez iminentemente assimétrica. Em suma, o que para o primeiro é tomado como evidente e como informação para uma prática social, para o último só existe como ilusão, pois que escamoteia um horizonte que não pode ser reduzido a uma dualidade. Contra essa imagem de uma "cortina de fumaça", Maybury-Lewis (1960) alega que Lévi-Strauss, para se referir ao problema do dualismo, haveria reunido dimensões incomparáveis como as estruturas diametrais e concêntricas ${ }^{14}$ quando, de fato, elas dizem respeito, respectivamente, a uma visão segmentada e não-segmentada da sociedade e não perfazem uma relação de subordinação da última pela primeira. Na introdução de D ialectical societies, volta a insistir que "eles [os povos jê e bororo] afirmam explicitamente que as suas sociedades são imbuídas de oposições, pois a oposição é imanente à natureza das coisas" (1979: 13; grifos meus). 
Ao contrário de Lévi-Strauss, o objetivo da análise de Maybury-Lewis é, portanto, verificar "como cada sociedade trabalha para criar uma síntese harmônica a partir de idéias, categorias e instituições antitéticas que constituem o seu modo de vida" (idem).

Mas para Lévi-Strauss, há algo entre a experiência e a realidade subjacente que requer a apreensão pelos modelos explicativos do antropólogo, contudo, esse esforço não pode ser mais que aproximativo: a realidade só pode ser conhecida mediante uma racionalização, também uma simplificação das nuanças nelas entranhadas que visa à captura de certos aspectos invariantes. É assim que, a propósito de sua interpretação do dualismo bororo, Lévi-Strauss (1993a [1960]) rebate as críticas de Maybury-Lewis no referido artigo de 1960, conferindo relevância ao seu método:

O diagrama relativo aos Bororo não fornece uma representação exaustiva de seu sistema social: nenhum diagrama poderia fazêlo e não é este o seu objeto. Mas representa pelo menos o essencial, ou seja, como nos é pedido, por um lado o par de metades, por outro lado uma tríade de grupos endógamos. Um diagrama não pretende mostrar tudo; basta que ilustre funções também presentes nos exemplos ilustrados por outros diagramas, a despeito do fato de que essas funções se manifestam em setores diferentes da realidade social para cada caso considerado. (: 87)

O autor aponta os preconceitos "naturalistas" presentes em seus críticos da escola britânica, que tenderiam a reificar um conceito de sociedade que não pode ser encontrado no mundo senão como atividade de pensamento. Respondendo a Maybury-Lewis (1960), que alegava não ser possível representar as relações sociais por símbolos formais como na matemática, Lévi-Strauss pergunta-se sobre o que de fato são essas relações senão uma construção abstrata do analista, que estabelece a diferença entre a observação empírica e os símbolos que usa para substituí-los. Isso não significa, entretanto, excluir da análise a experiência em detrimento de uma pura abstração. "Sem dúvida, a experiência deve ter a última palavra" (: 88), acentua Lévi-Strauss, mas 
desde que ela seja guiada pelo raciocínio, que não pode jamais apreendêla em sua forma bruta. Como as moléculas reais, invisíveis a olho nu, que interessam aos físicos, assim deveria ser pensada a realidade social: as relações sociais se oferecem como matéria prima para a construção dos modelos analíticos, capazes de tornar manifesta a estrutura social.

Por trás desse debate epistemológico, reside outro de natureza mais teórica sobre o estatuto do princípio de reciprocidade, do qual Lévi-Strauss faz derivar o dualismo. 0 dualismo tanto sociológico como metafísico é, para este autor, uma manifestação singular do princípio transcendental de reciprocidade - 0 imperativo da troca - em um plano diverso da troca de cônjuges. Esse ponto é sustentado nos textos de 1976 [1956] e 1960 (1993a) e desenvolvido, tendo em vista conseqüências diversas, em H istória de linœ (1993b). Maybury-Lewis, à sua parte, não corrobora com essa conclusão, tomando, de maneira explícita, em The attraction of opposites (Maybury-Lewis eAlmagor, 1989), a reciprocidade como função e não causa do pensamento dualista. Essa discordância possui desdobramentos importantes. Lévi-Strauss (1993a [1960]) acusa Maybury-Lewis de negligenciar a hierarquia e assimetria como problemas teóricos ao alegar que 0 modelo indígena procura reduzi-las a uma solução de equilíbrio. Para o primeiro, é preciso compreender que os sistemas binánios emergem como casos particulares de um sistema ternário, o que representa um "meio de exemplificar grandemente a teoria geral da reciprocidade, conforme confirmaram os matemáticos com quem discutimos o problema" (: 82). Ora, se a noção de reciprocidade está "tão firmada quanto a lei da gravidade para a astronomia" (idem), então, a novidade, ao contrário do que pensavam Malinowski e Radcliffe-Brown, é que não pode haver simetria quando a troca é a questão. Em outras palavras, a noção de assimetria seria inerente à de reciprocidade e, nesse caso, a produção de arranjos simétricos só pode ser compreendida como derivação de um problema assimétrico primeiro. O concentrismo deveria, assim, ser compreendido como logicamente anterior às formas diametrais - em tal sistema, a diferença se revela moto-contínuo da vida social. 
Se, para Lévi-Strauss, assimetria inerente à troca é condição para 0 dualismo, seja qual for a sua manifestação, para Maybury-Lewis o que se dá é propriamente o contrário: o dualismo é necessariamente um contraponto à hierarquia e à assimetria, cumpre a ele instaurar a simetria $\mathrm{e}$ a reciprocidade. A corrida de toras, praticada pelos Xavante, pelos Xerente e pelos Timbira consiste, para 0 autor, em um exemplo célebre de como uma aparente situação de competição pode sucumbir ao ideal de simetria. Um tronco de palmeira de dois metros é cortado a alguma distância da aldeia; um membro de cada metade - no caso dos Xerente, há as chamadas "metades esportivas", ao passo que entre os Xavante, o torneio se dá entre metades de idade ${ }^{15}$ - corre em direção à aldeia com a tora em seus ombros, e quando se cansa, apóia-se nos ombros de seu colega de metade; por fim deposita-a no local de encontro dos homens maduros no centro da aldeia. Essa descrição leva a crer que "as corridas de tora são, assim, performances explicitamente designadas para mostrar que o equilíbrio e a harmonia podem ser criadas a partir de um fluxo de eventos desordenado e contínuo" (1989: 103).

Produtoras de hostilidade e de um idioma bélico à primeira vista, essas manifestações consistem na atualização de ideologias de equilíbrio derivadas de uma teoria da harmonia cósmica, na qual a sociedade figura como parte de um esquema maior de coisas. Eis o lugar do dualismo, como imaginado pelo autor: uma teoria social que prevê a distribuição simétrica de itens de natureza antitética. Tal vontade de simetria se encontra na mente das pessoas e é por meio dela que se constrói o sentido de viver em coletividade.

Nota-se que, por mais que haja aproximações, os pressupostos teóricos enrijecem o debate. Se Maybury-Lewis entrevê uma predisposição à harmonia que deve ser obtida pela complementaridade e simetria entre os elementos contrários, Lévi-Strauss concebe o social como cindido por uma assimetria e uma incompletude fundantes. 0 primeiro vê no pensamento dualista a realização de uma certa utopia social - isso explica o recurso a uma imagem inspirada em Marx de A ideologia alemã: 
Revista de Antropologia, São Paulo, USP, 2002, v. 45 no 2.

Os Jê e os Bororo poderiam literalmente viver o seu sonho. Em tais sociedades, indivíduos poderiam seguir suas tarefas cotidianas, como caçare coletar, lutar e fazer amor, e ao mesmo tempo assumir papéis no drama da oposição e da resolução, da antítese e da harmonia, que configuram a sua visão de mundo. (Maybury-Lewis, 1979: 42)

Já Lévi-Strauss se afasta dessa imagem para pensar esse pensamento em sua tarefa sisífica: 0 dois jamais é completado na experiência, a não ser sob a forma de uma racionalização imperfeita, e o dualismo representa, nesse esquema, um limite para o ternarismo. Como informa o caso bororo, o concentrismo promove a mediação entre a forma diametral e a triádica, à medida que se mostra diádico como o primeiro e assimétrico como o segundo. 0 dualismo bororo, assim apresentado, "não basta a si mesmo e deve referir-se sempre ao meio que o circunda" (1976 [1956]: 177). Em analogia com as formas dos matemáticos, Lévi-Strauss afirma que o concentrismo pode ser representado pela oposição entre um ponto e uma reta, entre uma série contínua e outra descontínua, pois está fundado em um princípio de assimetria: as díades consistem antes em um disfarce para as tríades, um subterfúgio lógico que trata como dois termos homólogos um conjunto formado na realidade por objetos de natureza dessemelhantes.

A primazia do concentrismo sobre a simetria, destacada no texto de 1956, reaparece, em H istória de linœ, sob o tema da dualidade irredutível que se faz notar na mitologia de ambos os hemisférios das Américas. O mecanismo lógico dos mitos - moto-contínuo de contradições cujo terceiro termo, introduzido para promover a resolução, repõe imediatamente uma nova contradição ${ }^{16}$ - ganha conteúdo metafísico; em outras palavras, a mitologia ameríndia torna evidente a impossibilidade de viver sem a diferença, que é também uma impossibilidade de promover o equilíbrio entre elas. A mensagem dos mitos consiste em afirmar que onde há diferença sempre haverá instabilidade e 0 equilíbrio permanecerá como horizonte inatingível. A recusa do mito tupinambá, parafraseado pelo autor, em tornar os gêmeos semelhantes entre si, fazendo 
que eles sejam gerados por pais diferentes no ventre da mesma mãe, reflete essa necessidade de desdobramento ao infinito das diferenças, e jamais sua supressão, o que remete à operação de um "clinâmen filosófico para que em todo setor do cosmos ou da sociedade as coisas permaneçam em seu estado inicial e que, de um dualismo instável em qualquer nível que se apreenda, sempre resulte um outro dualismo instável" (Levi-Strauss, 1993b [1991]: 209).

Ambos, Maybury-Lewis e Lévi-Strauss, concebem o dualismo como um sistema de diferenças, contudo, em um caso, essas diferenças tendem ao equilíbrio e desenham um sistema por assim dizer homeostático, ao passo que, no outro, perfazem um movimento contínuo de multiplicação que implica o estado de desequilíbrio constante, a impossibilidade de uma totalização e a necessidade de uma abertura desse sistema ao meio que o circunda. Essas imagísticas diferentes encerram, ademais, um debate propriamente etnológico. Se o dualismo existe como um pensamento que se nutre da diferença e recusa toda unidade, ele se encontra distribuído de modo distinto segundo um e outro autor. Maybury-Lewis, que derivou a questão de um problema específico à paisagem centro-brasileira, passou a considerar, em The attraction of opposites, sociedades situadas em outras paisagens como sociedades que cometem também o dualismo em suas filosofias sociais; não obstante, nega-se em identificá-lo como propriedade intrínseca do pensamento dos povos indígenas americanos, como faz Lévi-Strauss em $\mathrm{H}$ istória de lince levando adiante uma intuição presente já em seus primeiros textos ${ }^{17}$. Essa nova discordância se dá por razões já levantadas: MayburyLewis não buscou evidências do dualismo na teoria e prática social de outros povos ameríndios ${ }^{18}$, como os de língua tupi-guarani, ao passo que Lévi-Strauss continua a perseguir os aspectos mais subterrâneos dessas teorias e, assim, os passos da transformação das estruturas míticas que perpassam as paisagens americanas do noroeste da América do Norte ao Chaco $^{19}$. 
Revista de Antro pologia, São Paulo, USP, 2002, v. 45 no 2.

$* * *$

A trajetória de Maybury-Lewis não se resume às suas reflexões sobre a dimensão do pensamento social dos povos indígenas centro-brasileiros, porém revela experiências ligadas ao campo da atuação política. Em 1972, ele, sua esposa Pia e mais dois professores de Harvard fundavam a Cultural Survival, uma organização não-governamental empenhada em defender os direitos dos povos indígenas das mais díspares regiões do mundo ${ }^{20}$. Na década de 1960, a demanda por ações dessa natureza tornava-se gritante devido ao impacto brutal do desenvolvimento e do discurso desenvolvimentista não raro apoiado sobre a concepção das sociedades não ocidentais como obstáculos e empecilhos ao progresso. Tendo essa situação em vista, era preciso desdobrar a reflexão acadêmica em um trabalho de assistência, visando suprir demandas dessas sociedades, e de divulgação, para um público mais amplo, de um conhecimento capaz de informar e afastar preconceito ${ }^{21}$.

Embora mergulhado em projetos de assistência, Maybury-Lewis sempre questionou o abandono de temas antropológicos clássicos em proveito da consideração de questões exclusivas para uma atuação política. Por certo, ele compartilharia a idéia de Bruce Albert (1995) de que não se trata de promover uma Antropologia propriamente aplicada, mas sim uma Antropologia implicada com os povos estudados, o que não significa que só se possa estudar os problemas enfrentados pelos indígenas em seu enfrentamento com a sociedade nacional. Em outras palavras, a sensibilidade para os contextos políticos nos quais os indígenas se vêem inseridos não deve excluir a investigação etnológica em seus moldes tradicionais. Como afirmava no prefácio à edição brasileira de A sociedade x avante:

Rejeito categoricamente a idéia de que as duas atividades sejam mutuamente exclusivas e creio indefensável a insistência doutrinária em qualquer uma delas. Não aceito o estudo dos povos indígenas no Brasil sem que seus problemas e suas soluções sejam também de interesse do 
investigador. Por outro lado, uma profissão de fé na atuação indigenista acompanhada de desinteresse pelo estudo das culturas dos povos indígenas (que é o que permite a compreensão de seus modos de ser específicos) é algo extremamente paternalista. Nossa dívida para com esses povos nos exige que os levemos a sério e isso significa dizer que devemos fazer todo o possível tanto para compreendê-los em seus próprios termos quanto para defender seu direito de viver no Brasil multiétnico do fundo. (1984: 9)

A lição do autor é, portanto, de que conhecimento produzido pela academia sobre os povos indígenas é o primeiro passo para que lhes seja restituído o respeito perdido no decorrer da história. 0 segundo seria a luta para que os modos de pensar e viver próprios desses povos possam conviver plenamente no interior de uma sociedade estatal, tendo em vista a maneira pela qual esta tem os subjugado tratando-os como estrangeiros e inferiores. Não obstante, tal a proposta de Maybury-Lewis, o Estado deverá tornar-se, ao contrário do que se verificou nos últimos tempos, um Estado multiétnico capaz de abrigar diferenças culturais por vezes profundas. A essa altura, depara-se com uma questão que intriga há muito a Antropologia: como é possivel fazer com que as diferenças convivam sob a égide de um mesmo Estado? A resposta de Pierre Clastres, em A sociedade contra o E stado (1978 [1974]), já havia sido categórica: a natureza do Estado é contraditória em relação à das sociedades primitivas, visto que o primeiro busca subsumir as disparidades sob o jugo arrasador do Um, ao passo que as últimas lutam para deter esse movimento em proveito da fragmentação das coletividades e da liberdade dos homens, revelando-se, assim, contra o Estado, contra a idéia de que seja possível abolir as diferenças em nome de uma entidade fantasmagórica. Para Clastres, a presença do Estado redunda não raro no etnocídio, uma aversão a outrem que explica, ao seu modo, o triunfo da colonização européia nas Américas. Malgrado essa visão fatalista, cujos pressupostos não lhes são absolutamente estranhos, Maybury-Lewis parece entrever alguma saída - reside aí o sentido do seu ativismo. 
Revista de Antropologia, São Paulo, USP, 2002, v. 45 no 2.

A proposta da criação de Estados multiétnicos deve partir da premissa de que "não há lei natural que impeça que 'nacionalidades' ou o que hoje chamaríamos de grupos étnicos convivam num único Estado" (MayburyLewis, 1984: 103). D essa feita, a asserção habitual, tanto na visão denunciadora - Clastres e os autores da "corrente do etnocídio" (Taylor, 1998 [1984]) - como na perspectiva desenvolvimentista - o entusiasmo para com o progresso e o processo de homogeneização - , de que as demandas do Estado são necessariamente contraditórias com as aspirações dos grupos étnicos deve ser revista considerando-se alternativas para a relação entre os Estados nacionais e as minorias étnicas. Com Maybury-Lewis, a espera e o estímulo para o desaparecimento das culturas indígenas, sob o pretexto de que estas emperram o processo do desenvolvimento, podem ser contornados. Assim, é preciso não se ater unicamente a denúncias, mas estabelecer antes de tudo um plano de ação. 0 Estado não é em essência 0 Leviatã; pode, ademais, deixar de sê-lo se os integrantes da sociedade civil estiverem dispostos a transformar essa realidade.

0 projeto político de Maybury-Lewis, que transparece em artigos como "Vivendo Leviatã: grupos étnicos e o Estado" (1984) ou no livro Indigenous peoples, ethnic groups and the State (1996), reside em fazer valer 0 ponto de vista dos nativos no interior de um sistema que foi decretado como não reservando lugar a eles. Trata-se, em outras palavras, de um projeto de resistência que visa construir um espaço de convivência onde as diferenças não sejam subsumidas à lógica da unidade, onde elas possam ser vistas menos como mutuamente excludentes que como fundamentalmente complementares. O ra, o projeto político desse antropólogo - e por que não a sua utopia? - restitui em um plano global o que o dualismo centro-brasileiro promovia em uma dimensão local, a aldeia. É curioso, assim, reencontrar o sentido de um tema caro à sua Etnologia em uma terra devastada pelo discurso do desenvolvimento e da globalização, o discurso do Um, para voltar a Clastres. Em The attraction of opposites (Maybury-Lewis e Almagor, 1989), o dualismo como ideologia é apresentado como maneira eficaz de controlar a his- 
tória - Maybury-Lewis compactua, ao seu modo, com a idéia de "sociedades frias" - e assume como maior inimiga a modernidade, visto que esta não cessa de impor fluxos diversos e um movimento de fragmentação que lhe são estranhos - o dualismo é, sob essa definição, um holismo.

Maybury-Lewis demonstra como em situações de crise demográfica e de intenso contato com a sociedade brasileira, os dualismos são constantemente recriados, comprovando a idéia de que o modelo continua na mente dos agentes por mais que possa parecer ausente. Entre os Xavante e os Kayapó, o autor aponta a criação de novos sistemas de metades que sinalizam o uso político de sistemas binários que derivam das "teorias sociais que podem acomodar as mudanças mais dramáticas e ainda continuam a determinar a prática social" (1989: 106). 0 dualismo é, pois, o que garante a harmonia no momento do caos, o que impede que as sociedades sucumbam ao fluxo desordenado, à entropia. Em sua experiência da modernidade, as sociedades jê e bororo tiveram de aprender que o dois - no plano local - é condição para o múltiplo - em escala global. Para que permaneçam, elas precisam manter de maneira complementar e balanceada tanto as diferenças internas (em cada aldeia) como as externas (entre as aldeias e o mundo dos brancos) - os Jê e Bororo de Maybury-Lewis não parecem ter a alma inconstante como os Tupi de Viveiros de Castro (1992), embora tendam a concordar com uma meditação dos G uarani de Clastres (1978 [1974]), qual seja, a de que "o Mal é o Um. 0 Bem não é o múltiplo, mas o dois, ao mesmo tempo o um e seu outro, o dois que designa verdadeiramente os seres completos" (: 121).

A lição de Maybury-Lewis diz respeito ao fato de que o mundo moderno - o Estado, a ciência, a sociedade civil etc. - tem muito a aprender com as sociedades que pensam dualisticamente (obviamente, não apenas com estas) e, para tanto, deveria começar a lhes fazer justiça, assistindo aos seus movimentos de resistência que não devem ser meramente importados do $O$ cidente, pois que emergem no do seio de suas próprias ideologias. 0 mundo moderno deveria, para usar uma expres- 
são de Viveiros de Castro (1981), "dar ouvidos" a essas sociedades, quebrando a situação de incomunicabilidade há muito instaurada e aceitando seus membros como sujeitos de seu próprio destino. Nesse final paira, contudo, uma questão: seria esse projeto, o da convivência harmônica das diferenças no interior de um mesmo Estado nacional, uma utopia realizável ou, para voltar ao debate com Lévi-Strauss sobre 0 caráter ontológico do dualismo ameríndio, mais uma tarefa sisífica, mas que nem por isso deve ser abandonada? Diante dessa inquietação, Maybury-Lewis parece optar pela alternativa mais otimista, buscando fazer valer o seu próprio demônio sobre a experiência do mundo.

\section{Notas}

1 "Nimuendaju dedicou-se à descrição minuciosa de sociedades indígenas específicas, consagrando-se como o etnógrafo de campo que mais conheceu grupos indígenas diferentes no Brasil” (G rupioni, 1998: 167).

2 The A pinayé (1939), The Sherente (1942) e The eastern Timbira (1946).

3 Lowie deu destaque ao caso A pinayé, entre os quais Nimuendaju havia observado uma anomalia - uma regra de descendência paralela operante em um sistema de quatro classes matrimoniais (os meninos pertenciam ao grupo do pai, ao passo que as meninas, ao grupo da mãe). Tratava-se de algo jamais etnografado em outra sociedade e que contradizia o princípio (universal) de equivalência de germanos firmado por Radcliffe-Brown. Maybury-Lewis (1979) e sobretudo Roberto D a Matta (1973) dedicam-se a esclarecer esse mal-entendido. Segundo D a Matta, a idéia de que um homem não pertencia à mesma metade de sua irmã seria de fato uma ilusão propiciada pela observação pouco cuidadosa de Nimuendaju. A questão reside no fato de que, no Brasil Central, noções como descendência, tal como definidas nos estudos clássicos sobre aÁfrica, dos quais Radcliffe-Brown foi o grande fundador e em torno dos quais gravitava a Antropologia da época, não pareciam dar conta da imensa complexidade das relações sociais estabelecidas no Brasil Central. As conclusões de Da Matta revelavam que em casos como o apinayé, as metades observadas não correspondem a classes matrimoniais, afastando-se por isso dos casos australianos em que se 
vislumbra expressões da troca restrita. D essa maneira, não era possível estender o modelo dualista clássico à América do Sul, e, quem quisesse fazê-lo, haveria de redefinir a própria noção de dualismo.

4 Para uma discussão sobre a vinda de Lévi-Strauss ao Brasil, cf. Peixoto (1998) e Grupioni (1998).

5 Em seu estudo bastante citado sobre os G uarani, Schaden (1974 [1954]) busca encontrar os "aspectos fundamentais" da cultura nativa a despeito dos efeitos desagregadores do contato com o mundo dos brancos. Schaden concebe "cultura" como uma totalidade harmônica; assim, nesse trabalho, o desafio consiste em procurar 0 que teria restado, diante das mudanças acarretadas pela situação histórica, dessa totalidade, reduzida aos seus aspectos fundamentais.

6 Na introdução de A mitologia heróica de tribos indígenas do Brasil (1989 [1945]), livro caracterizado por uma construção explicativa híbrida, Schaden admite: "Não nos quisemos filiar a nenhuma escola [...] para deixar o material falar por si [...] afastando quaisquer especulações ousadas, afirmações dogmáticas ou meros pontos de vista" (: 10). Em um pequeno depoimento publicado no A nuário A ntropológio de 1982, ele acrescenta: "Nunca chegou a esboçar-se, felizmente, na Universidade de São Paulo, algo que pudesse denominar-se 'escola antropológica paulista'. Por certo, os interesses foram sempre variados, com tendência crescente para estudos interdisciplinares. D esde cedo se acentuou, no entanto, a perspectiva sociológica, por influência, sobretudo, de Claude LéviStrauss" (:254).

7 Não fiz referência a Florestan Fernandes (1970), que em 1952 publicavaA funçoo social da guerra entre os T upinambá e já era considerado uma figura importante da sociologia uspiana, pois Maybury-Lewis, na época de sua estadia em São Paulo, não havia travado contato com ele e sua obra (ver depoimento abaixo). Como sustenta Viveiros de Castro (1999), Fernandes foi o precursor da etnologia indígena no Brasil, uma vez dedicado a reconstituir o sentido e a totalidade da experiência social de um povo de língua tupi-guarani no século XVI. Ele foi, ademais, capaz de escrever uma monografia completa, com o rigor científico e etnográfico exigido, valendo-se de documentos e crônicas lidos à luz das discussões tanto da Escola Sociológica Francesa de D urkheim e Mauss como do estrutural-funcionalismo de Radcliffe-Brown e seus discípulos. 
8 As duas grandes obras de referência no período eram a coletânea organizada por Radcliffe-Brown, Sistemas africanos de descendência ecasamento (1950), e o livro de Claude Lévi-Strauss, A s estruturas elementares de parentesoo (1982 [1949]) - fontes de duas teorias conflitantes, a teoria da descendência e a teoria da aliança, respectivamente. A primeira baseava-se na etnografia africana e tomava os dados da descendência como fundantes de todo o sistema de parentesco, ao passo que a segunda guiava-se por etnografias de diferentes regiões da $\mathrm{O}$ ceania e da Ásia para sustentar um modelo baseado na anterioridade das regras de casamento em relação às de filiação (cf. D umont, 1997 [1970]).

9 Este livro foi traduzido para o português, em 1984, por A racy Lopes da Silva, que foi aluna de Maybury-Lewis em Harvard e levou adiante os estudos sobre os X avante, publicando, em 1986, o livro N omes e amigos: da prática x avante a uma reflexão sobre os Jê, além de vários artigos, e orientando teses e dissertações sobre este povo. A divulgação das idéias de Maybury-Lewis no Brasil e especialmente em São Paulo devem-se a ela.

10 Jean Carter Lave estudou os Krikati e Júlio César Melatti, os Krahó, ambos Timbira O rientais. Roberto D a Matta realizou sua pesquisa entre os Apinayé (Timbira $O$ cidentais), Joan Bamberger e Terence Turner, entre os Kayapó (Jê setentrionais), eJ. C. Crocker, entre os Bororo.

11 A "dissolução culturalista" apontada por Viveiros de Castro (1993) parece ter marcado as gerações que sucederam o Projeto Harvard, não apenas de jê-ólogos - como se faz notar, entre outros, nos trabalhos de Anthony Seeger (1980) sobre os Suyá e de Aracy Lopes da Silva (1986) sobre os X avante - mas também de amazonistas. Uma decorrência dessa inflexão culturalista pode ser encontrada em um artigo síntese de autoria de Anthony Seeger, Roberto D a Matta e Eduardo Viveiros de Castro (1987 [1979]) - "A construção da pessoa nas sociedades indígenas brasileiras" - no qual se propõe que, em vez de tomar as teorias da aliança e da descendência como chaves de explicação, era necessánio antes buscar teorias da pessoa humana, teorias da concepção, preceitos subjacentes a rituais de iniciação e funerais etc. Mais recentemente, uma conseqüência desse debate pode ser encontrada no estudo da "construção do parentesco" ameríndio realizado por Viveiros de Castro (2001). 
12 É possível ler D ialectical societies de vários modos. De um lado, há o modelo standard apresentado por Maybury-Lewis e, de outro, os afastamentos mais ou menos significativos dos demais autores - para uma discussão sobre a relação entre os vários modelos presentes na coletânea, ver Cohn (2001). Por ora, apresento apenas o debate entre Maybury-Lewis eTurner, que apresentam posturas muito diversas.

13 Resulta daí que a "dialética" referida por Maybury-Lewis no título de sua coletânea sobre os grupos jê e bororo não pode ser tomada segundo a lógica hegeliana, pois não supõe a relação entre elementos contraditórios, mas sim contrários. Sobre esse aspecto, ver a discussão, na introdução de The attradion of opposites (Maybury-Lewis \& Almagor, 1989) em que o autor aproxima o dualismo como pensamento ao taoísmo chinês, sistema baseado na interação entre elementos opostos e complementares (o yin e o yang, o masculino e o feminino, e assim por diante).

140 dualismo diametral conserva o valor equistatutário, por exemplo, para cada metade que compõe a aldeia. $\mathrm{O}$ dualismo concêntrico, por sua vez, opera segundo uma oposição gradual e hierárquica, uma vez que supõe um termo englobado (a periferia) e um termo englobante (o centro).

15 Para uma discussão crítica sobre a relação da corrida de toras com o dualismo entre os Xavante, cf. Vianna, 2002.

16 Tal é a tese de Lévi-Strauss no artigo programático "A estrutura dos mitos" (1976 [1955]).

17 Ver, por exemplo, "On dual organization in South America" (1944) e Tristes trópioos (1957 [1955]) em que Lévi-Strauss está sobretudo interessado em meditar sobre a história cultural do continente americano.

18 Embora, na introdução a The attraction of opposites, Maybury-Lewis (1989) cite 0 caso andino como merecedor de destaque no estudo de idéias e instituições dualistas. Sobre a dificuldade de inserir os grupos tupi-guarani nas discussões sobre o dualismo, cf. Seeger, 1989, na mesma coletânea.

19 O que faz Lévi-Strauss em $\mathrm{H}$ istória de linœ é apreender o espírito humano em 
sua face ameríndia ou, em outras palavras, refletir sobre o dualismo como se ele fosse uma incarnação para o pensamento ameríndio do problema posto por assim dizer universalmente do princípio da reciprocidade. Para uma discussão desse tema, cf. Sztutman, 2001.

20 Hoje em dia, a Cultural Survival dedica-se prioritariamente a pesquisas sobre povos indígenas, privilegiando estudos de caso. Além desse pólo, destacam-se os programas de assistência jurídica e de educação. A instituição conta também com publicações periódicas e boletins informativos. Para mais detalhes, cf. www.culturalsurvival.org.

21 Maybury-Lewis organizou duas publicações sobre diferentes povos indígenas do globo dirigidas ao grande público: M illenium: tribal wisdom and themodern world (Viking Press, 1992), que teve origem em uma série televisiva homônima, e Peoples of the world (editado com Brian Fage e Wade D avis pela série National Geographic Societies, 2001).

\section{Bibliografia}

ALBERT, B.

1995

“Anthropologie 'apliquée' ou 'impliquée'?" in BARÉ, J.-F. (org.), L es applications de l'A nthropologie, Paris, Harmattan.

CARNEIRO DA CUNHA, M.

1993

"Les études gê", L'H omme, 126-128.

CLASTRES, P.

1978 [1974] A sociedade contra o E stado, Rio de Janeiro, Francisco Alves.

COHN, C.

2001 “Os vários modelos jê", mimeo.

DA MATTA, R.

1973 U m mundo dividido: a estrutura social dos índios A pinayé, Petrópolis, Vozes. 
DA MATTA, R., SEEGER, A., VIVEIROS DE CASTRO, E.

1987 [1979] "A construção da pessoa nas sociedades indígenas", in O LIVEIRA, J. P., Sociedades indígenas e indigenismo no Brasil. Porto Alegre/ Rio de Janeiro, Marco Zero/ Editora da UFRJ.

DUMONT, L.

1995 [1966] H omo hierarcus, São Paulo, Edusp.

1997[1970] Groupes de filiation et alliance de mariage: introduction à deux théories d'anthropologie sociale, Paris, Gallimard.

FERNANDES, F.

1970 A função social da guerra na sociedade tupinambá, São Paulo, Edusp.

GEERTZ, C.

1978[1973] A interpretação das culturas, Rio de Janeiro, Zahar.

GRUPIONI, L.D.

1998 Coleções e expediçoes vigiadas: os etnólogos no conselho de fiscalização das expediçoes artísticas e científicas no Brasil, São Paulo, Hucitec/ ANPOCS.

\section{LÉVI-STRAUSS, C.}

1944 "On dual organization in South America", A merica Indigena, 4(1).

1948 L a vie familiale et sociale des indiens Nambikwara, Paris, Société des Américanistes.

1957 [1955] Tristes tropiques, Paris, Plon.

1976a[1952] "Estruturas sociais no Brasil Central e O riental”, in A ntropologia estrutural, Rio de Janeiro, Tempo Brasileiro.

1976b [1952] "A noção de arcaísmo em Antropologia”, in A ntropologia estrutural, Rio de Janeiro, Tempo Brasileiro.

1976 [1955] "A estrutura dos mitos", in A ntropologia estrutural, Rio de Janeiro, Tempo Brasileiro.

1976 [1956] "As organizações dualistas existem?", in A ntropologia estrutural, Rio de Janeiro, Tempo Brasileiro. 
1982 [1949] A s estruturas elementares do parentesco, Vozes, São Paulo.

1993a[1960] "O sentido e o uso da noção de modelo", in A ntropologia estrutural dois, Rio de Janeiro, Tempo Brasileiro.

1993b [1991] H istória de linœ, São Paulo, Companhia das Letras.

\section{LOPESD A SILVA, A.}

1986 N omes e amigos: da prática x avante a uma reflex ão sobre os Jê, São Paulo, FFLCH-USP.

MAYBURY-LEWIS, D.

1960 "The analysis of dual organizations: a methodological critique", Bijdragen tot de T aal-, L an- en V olk enkunde, 116.

1979 "Introduction", "Cultural categories of the central Jê", "Conclusion: kinship ideology and culture", in D ialectical societies: the G ê and Bororo of $\mathrm{C}$ entral Brazil, Cambridge, Massachussets, Harvard University Press.

1984 [1967] A sociedadex avante, Rio de Janeiro, Francisco Alves.

1984 "Vivendo Leviatã: grupos étnicos e o Estado", A nuário A ntropológico 83.

1989 "The quest for harmony", "Social theory and social practice: binary systems in Central Brazil", in MAY BURY -LEWIS, D . \& ALMAG OR, U. (orgs.), The attraction of the opposites: thought and society in dualistic mode, Michigan, University of Michigan Press.

1996 Indigenous peoples, ethnic groups and the state, Cambridge, Cultural Survival.

MAYBURY-LEWIS, D . (ORG .)

1979 D ialectical societies: the G êand B ororo of C entral Brazil, Cambridge, Harvard University Press.

1990 [1965] 0 selvagem e 0 inocente, Campinas, Unicamp.

MAYBURY-LEWIS, D . \& ALMAGOR, U. (ORG S.)

1989 The attraction of the opposites: thought and society in dualistic mode. Michigan, University of Michigan Press.

MERLEAU-PONTY, M.

1991 [1960] Signos, São Paulo, Martins Fontes. 
Renato Sztutman.Do Dois ao Múltiplo na TerRa do Um

NEEDHAM, R.

1962 Structure and sentiment: a test case in social anthropology, Chicago, Chicago University Press.

PEIXOTO, F.

1998

"Lévi-Strauss no Brasil", Mana, 4(1).

RADCLIFFE-BROWN, A.R.

1950

"Introdução", in Sistemas polítios de parenteso e casamento, Lisboa, Fundação Calouste Gulbenkian.

RIVIÈRE, P.

1969 M arriage among the Trio: a principle of social organization, Oxford, Claredon Press.

SCHADEN, E.

1989 [1945] A mitologia heróica detribos indígenas no Brasil: ensaio etnossociológico, São Paulo, Edusp.

1974 [1954] A spectos fundamentais da cultura guarani, São Paulo, Epu/ Edusp.

1982 "D epoimento", A nuário A ntropológion.

SEEGER, A.

1980

$\mathrm{N}$ ature and society in Central Brazil: the Suyá indians of Mato $\mathrm{G}$ rosso, Cambridge, Harvard University Press.

1989

"D ualism: fuzzy thinking or fuzzy sets?", in MAYBURY -LEWIS, D . \& ALMAGOR, U. (orgs.), The attraction of the opposites: thought and society in dualistic mode, Michigan, University of Michigan Press.

STEWARD , J.

1948 [1945] H andbook of South A merican indians, Washington D C, Smithsonian Institution, v.7.

SZTUTMAN, R.

2001 "Lévi-Strauss e o desafio americanista”, São Paulo, Cebrap, mimeo. 
TAYLOR, A.-C.

1998 [1984] “O americanismo tropical, uma fronteira fóssil da etnologia?”, mimeo, tradução de Beatriz Perrone-Moisés.

TURNER, T.

1979

"The gê and bororo societies as dialectical systems: a general model", in MAYBURY-LEWIS, D . (org.), D ialectical societies. The G ê and Bororo of C entral Brazil, Cambridge, Massachussets, Harvard University Press.

1984 "D ual opposition, hierarchy and value: moiety structure and symbolic polarity in Central Brazil and elsewhere", in GALEY, J.-C. (org.), Différences, valeurs, hierarchie: textes offerts à Louis Dumont, Paris, EHSS.

VIVEIROS DE CASTRO, E.

1980

"Por uma antropologia mais real: a responsabilidade social do etnólogo", comunicação apresentadaà IV Reunião da ANPOCS, Rio de Janeiro.

1992 "O mármore e a murta: sobre a inconstância da alma selvagem”, Revista de A ntropologia, 35.

1993 "Alguns aspectos do dravidianato amazônico", in VIVEIRO S D E CASTRO, E. \& CARNEIRO DA CUNHA, M. (orgs.), A mazônia: etnologia e história, São Paulo, NHII-USP/ Fapesp.

1999 "E tnologia indígena", in MICELLI, S. (org.), 0 que ler nas ciências sociais, São Paulo, Sumaré, v.1: Antropologia.

2000 "Atualização e contra-efetuação do virtual na socialidade amazônica: 0 processo do parentesco", Ilha, 2/ 1.

VIANNA, F. L. DE B.

2002 A s toras, a bola e os brancos, São Paulo, dissertação de mestrado, Universidade de São Paulo.

WEBER, M.

1967

"A ciência como vocação", in Ciência epolítica: duas vocaọoes, São Paulo, Cultrix. 


\begin{abstract}
This article reaches a further understanding about the trajectory of the british anthropologist, living in USA, D avid Maybury-Lewis. It discusses some aspects of his intellectual formation, which includes a long period of research among the Xavante e and a comparative study on the gê and bororo speaking people of Central Brazil. Maybury-Lewis is a central character in the development of the so called "tropical Americanism". Among his ethnografical and theoretical contributions, one can quote the elaboration of a gê and bororo analythical model, the renovation of the kinship studies e and the reflection on the relationship between indigenous peoples and the State. A theme seems, in fact, to be present along all his work: the dual organizations. This was, in effect, the motive of a long debate with Lévi-Strauss' works, which will be here reviewed.
\end{abstract}

KEY-WORD S: Amerindian ethnology, gê and bororo speaking people, dualism, multiculturalism, State. 